\title{
Automation with renewable energy to optimize the exploitation of water supply networks in Ninh Thuan province
}

\author{
Anh Tuan $\mathrm{Vo}^{{ }^{*}}$, Lien Huong Mai ${ }^{2}$, and Huynh Thuy Ngan Nguyen ${ }^{2}$ \\ ${ }^{1}$ University of Architecture Ho Chi Minh City, 196 Pasteur steet, ward 6, District 3, Ho Chi Minh \\ City, Vietnam \\ ${ }^{2}$ Agency of Technical - Infrastructure, Ministry of Construction, 37 Le Dai Hanh street, Ha Noi, \\ Vietnam
}

\begin{abstract}
The research that was conducted on the water supply network of Phan Rang city, Ninh Thuan province, is aimed at using renewable energy to optimize the management and reduce the water loss. The research has conducted DMA (District Metering Area) setup, construction and installation of flow meter and pressure reducing valve chamber for flow and pressure control with active pressure regulation, and the use of hydraulic power generator to generate power at the site. Research results provide management agencies, in particular, water supply companies, with optimal solutions in network management and energy saving, reducing the amount of water loss effectively, thereby increasing revenue and saving clean water - precious resources are gradually depleted.
\end{abstract}

\section{Introduction}

Ninh Thuan Water Supply Joint Stock Company manages the water supply network of Phan Rang - Thap Cham city, Ninh Thuan province, with a population of 160,000 . The water resource used is the river water and the well water with 3 water treatment plants (WTPs) withtotal capacity of $61,300 \mathrm{~m} 3 /$ day, total length of distribution network is $21,700 \mathrm{~km}$ and serves for 75,689 people.

The current water supply network in Thap Cham is a round network with total flow managed through the WTPs, with a current water loss ratio of $20 \%$, including invisible loss and visible loss [16]. This reserach proposes solutions that help Ninh Thuan Water Supply Company manage its water supply network efficiently, save energy and reduce water loss.

The author proposes to divide the water supply network into 15 DMAs, which is a modern management solution [20]. Each district can be independently analyzed using flow meters and pressure transducers to improve system knowledge, to realize the water balance of the area, and to locate water losses. A DMA is a set of nodes enclosed in specified and permanent boundaries defined in order to install the smallest number of metering devices. DMAs identification is commonly realized using an empirical approach based on technical experience [20] even if new methods, survey sound leakage in water supply pipelines

*Corresponding author: voanhtuanus@yahoo.com 
periodically [21] orgraph theoretic and graph partitioning principles used in distributed computing have recently been proposed.

The equipment installed in the DMA for continuous monitoring of flow and pressure makes the water supply company easy to manage. Water supply network management is becoming more and more of a concern in Viet Nam, in the context of clean water resources is increasingly exhausted threatening national clean water security. But mainly on network research, water quality, hydraulic problems and water loss prevention, the equipment management of the water supply network has not been paid much attentionwhile the water equipment is often of high value. In practice, meter, data transmitters (water meters, pressure sensors and dataloggers) installed on the water supply network are mainly installed in underground sites, sometimes flooded difficult to get the power from the electricity where the main power source is the battery installed in the device. Batteries will be depleted after several years of use and must be replaced to ensure stable operation, the cost of replacement batteries often high due to imports from abroad. In this research, the author also recommends the use of hydraulic power generators to generate electricity for on-site consumption, prolong battery life, and save operating and maintenance costs.

The research also proposed a water loss solution for DMA Ngo Quyen, one of the 15 DMAs in Phan Rang - Thap Cham city. In previous researches, the author found that the majority of water losses occurred as mechanical water losses but mainly at the clamp saddle position, service connections $[10,11]$. Therefore, to reduce water loss, the study focused on reducing mechanical water losses, regulating the pressure in the DMA based on the partitioning management of the pipe network, such as the PMA (pressure management area) and DMA. PRVs (pressure reducing valves) are installed at the inlet of the PMAs or DMAs and the water pressure inside the zonal network can be regulated by operating the PRVs. To maximize the benefits of pressure management, the installation and operation strategies of PRVs, i.e. quantity, locations and opening adjustment, are optimized [12], when the pressure in the pipeline drops, the water leakage through the hole in the pipeline will decrease [19].

\section{Materials and methods}

\subsection{DMA setup and equipment installation}

DMA Ngo Quyen was selected with a pilot scale of 500 connections and did not specify the consumption as well as the leakage rate. DMA is set up by closing the boundary valves and installing the bulk flow meter chamber at the DMA input. This bulk flow meter has a pressure probe and a pressure reducing valve installed at downstream of meter to actively regulate the pressure in the DMA.

Equipment installed in DMA including:

1. Electromagnetic flow meter DN150

2. Hydroturbine to generate power

3. Pressure Reducing Valve(PRV) dualsetpoint

4. LS-V Datalogger to archive data (Flow, up- and downstream pressure) and control the PRV

$\mathrm{P} 1$ is upstream pressure, $\mathrm{P} 2$ is downstream pressure, $\mathrm{P} 3$ is critical point pressure (The critical point is the place in the zone in question (DMA or PMA) at which the lowest supply pressure occurs during the course of the day)

5. LS42 Datalogger to archive pressure at critical point

6. PCWIN2 SCADA software to store, view and analyze data 


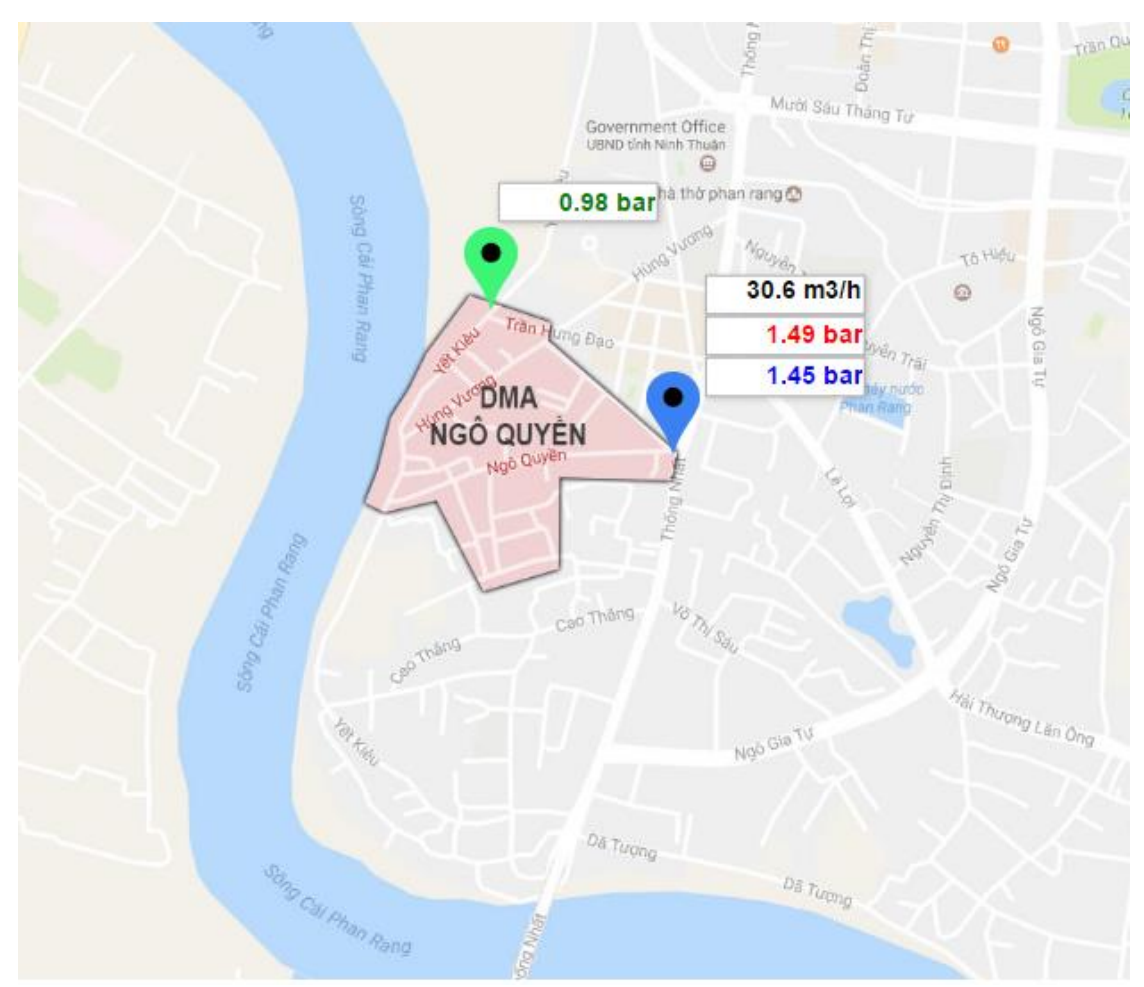

Fig. 1. DMA Ngo Quyen.

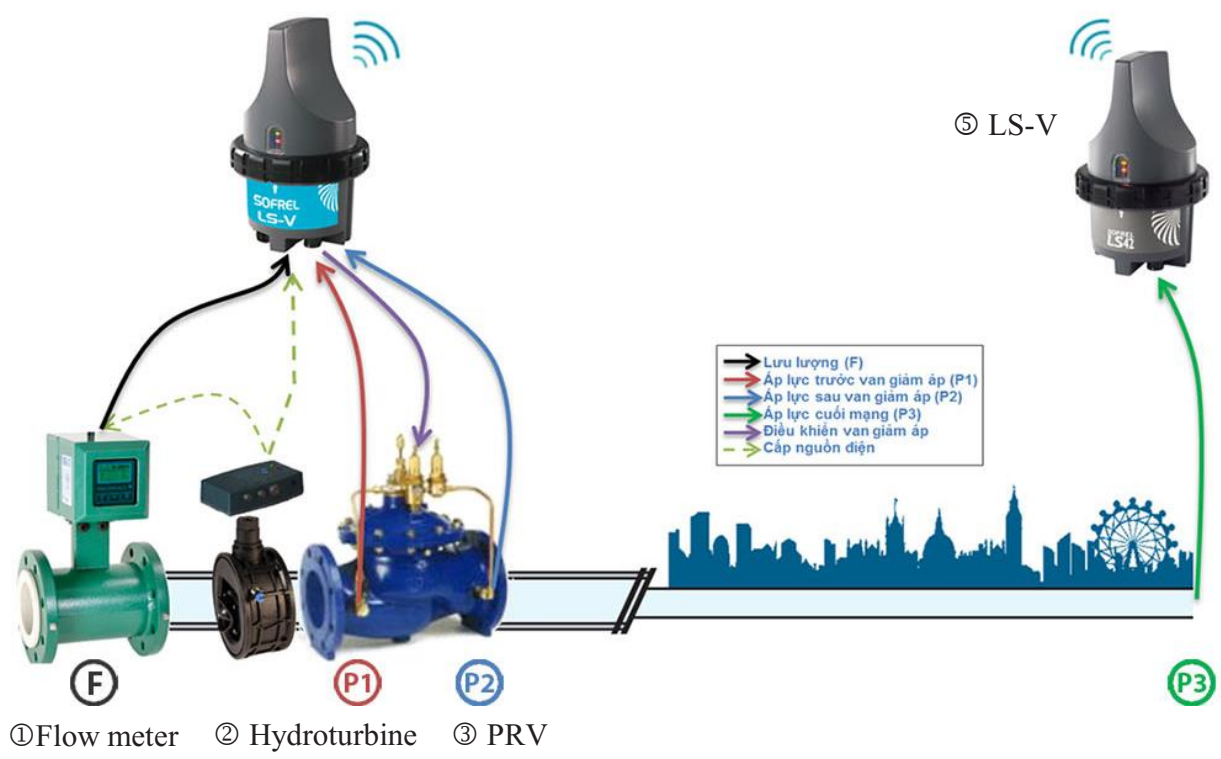

Fig. 2. Equipment in Water meter chamber - DMA Ngo Quyen. 
After installation of equipment, flow and pressure parameters in the DMA collected in 07 days as follows (from 03-06-2017 to 19-06-2017), the pressure valve in fully open mode
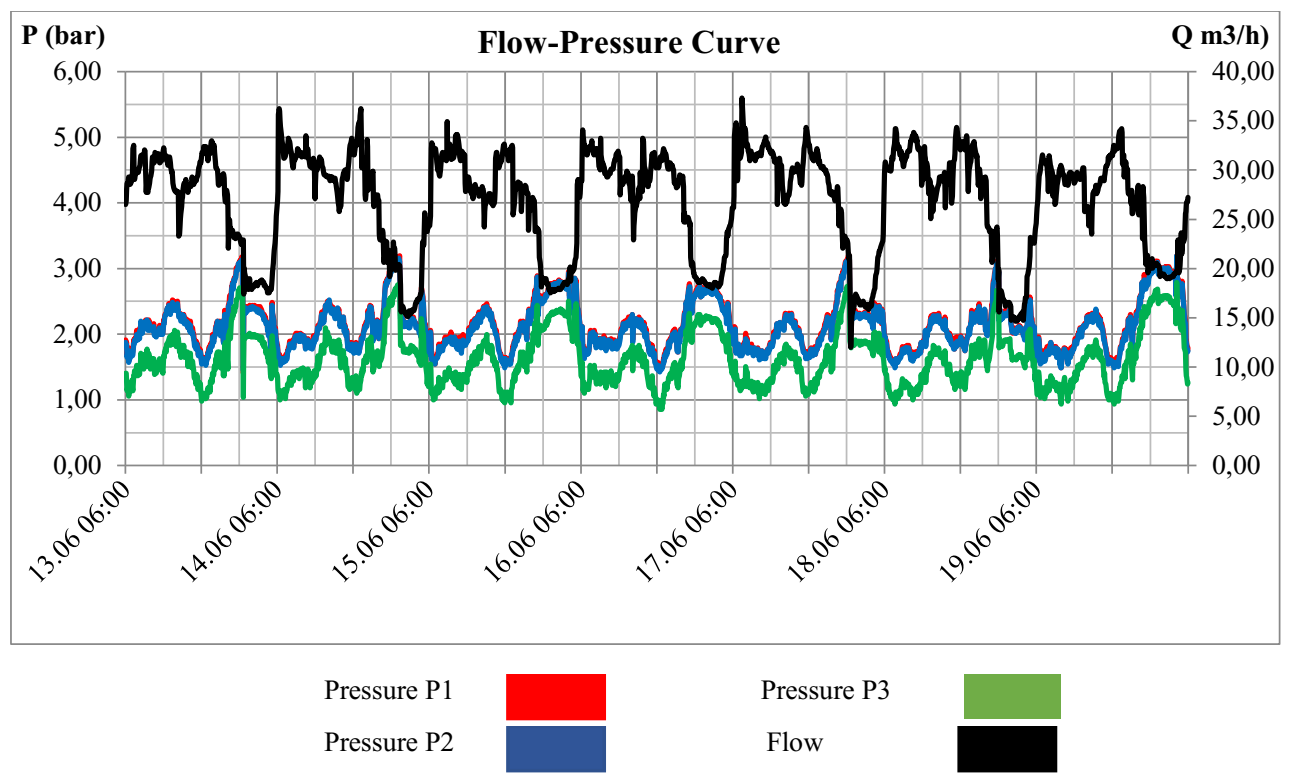

Fig. 3. Curve of Pressure - Flowrate after when pressure valve in fully open mode.

Table 1. Report of Pressure - Flowrate (From 13-06-2017 to 20-06-2017).

\begin{tabular}{|c|c|c|c|c|}
\hline & Flow & P1 Presure & P2 Pressure & P3 Pressure \\
\hline Max & $37.32 \mathrm{~m} 3 / \mathrm{hr}$ & $3.22 \mathrm{bar}$ & $3.20 \mathrm{bar}$ & $2.79 \mathrm{bar}$ \\
\hline Min & $12.00 \mathrm{~m} 3 / \mathrm{hr}$ & $1.40 \mathrm{bar}$ & $1.42 \mathrm{bar}$ & $0.85 \mathrm{bar}$ \\
\hline Avergrage & $26.85 \mathrm{~m} 3 / \mathrm{hr}$ & $2.14 \mathrm{bar}$ & $2.11 \mathrm{bar}$ & $1.63 \mathrm{bar}$ \\
\hline Avergrage per day & $644 \mathrm{~m} 3 / \mathrm{day}$ & & & \\
\hline
\end{tabular}

\subsection{Model setup}

\subsubsection{Hydraulic generator renewable energy}

Equipment used.

The research uses turbine-powered generator, the flowgoes through and turn the turbine to generate AC power, via a Hydrocharger and save the enegy in battery as DC power to supply to external devices. 

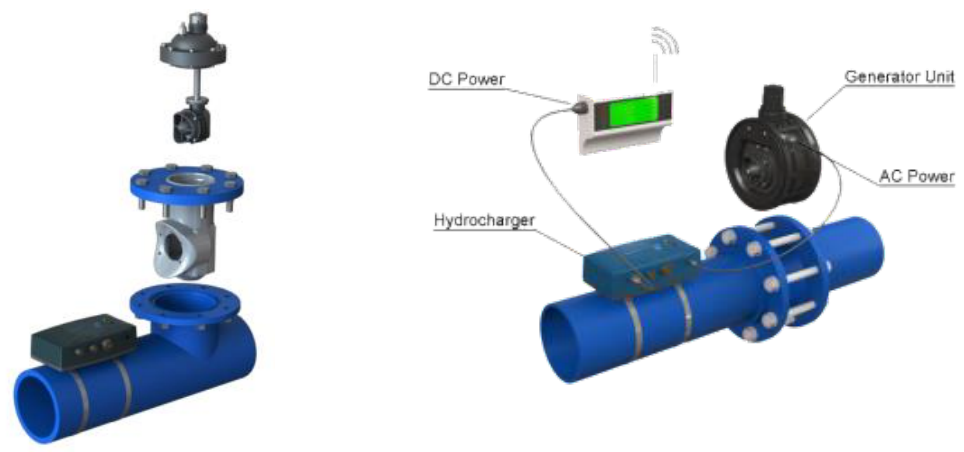

Fig. 4. Hydroturbine hydraulic generatorstructure.

This DMA uses Hydrospin 6" YOGEV 20W, the power generated and headloss versus flowrate as following:
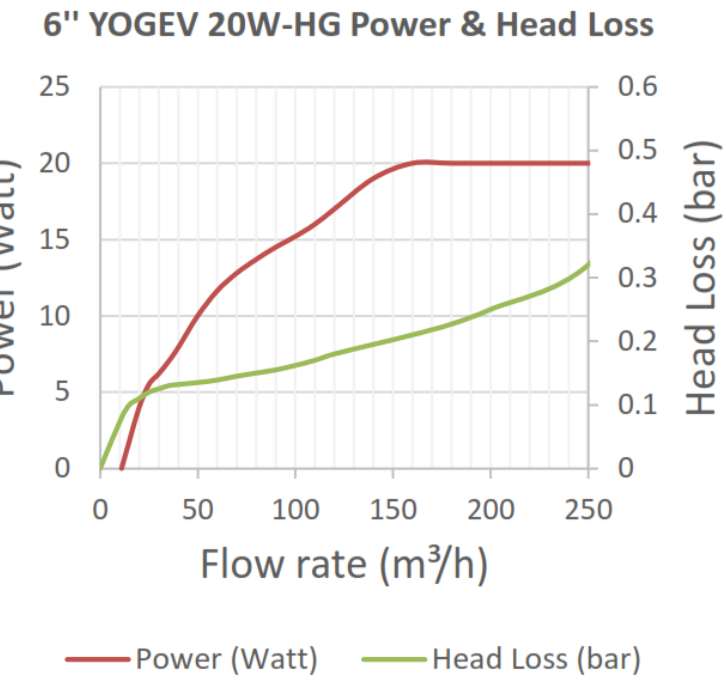

Fig. 5. Hydrospin 6" YOGEV 20WProducts Power Output- Power vs Flow-Rate \& HeadLoss.

Operating mode of the equipment

The equipment installed bulk meter chamber that requires power include: electromagnetic flowmeter and LS-V Datalogger. In which the electromagnetic flowmeterand LS-V operatecontinuity $24 / 7$, LS-V is set to send data of flow, up- and downstream pressure with interval of every 15 minutes.

Preliminary estimates of energy generated from hydroturbine, with a water flow of 580.86 $\mathrm{m} 3 /$ day (about $24 \mathrm{~m} 3 / \mathrm{h}$ ). With this flow rate, based on the table, the power generated is about $5 \mathrm{~W}$. ISOMAG electromagnetic flowmeter have a power consumption of about $4 \mathrm{~W}$, to ensure a stable and reliable metering, the author suggests that the meter be powered directly from the battery and that only the power from the Hydroturbine should be used for LS-V Datalogger.

\subsubsection{Adjusting pressure reducing valve to reduce water losses}

Pressure-flow results are recorded and displayed as curve plotting using the PCWIN2 SCADA software as follows: 
Table 2. Report of Pressure (From 13-06-2017 to 20-06-2017).

\begin{tabular}{|l|r|r|r|}
\hline & P1 Presure & P2 Pressure & P3 Pressure \\
\hline $\begin{array}{l}\text { Max } \\
\text { 02:00-04:00 a.m }\end{array}$ & $3.22 \mathrm{bar}$ & $3.20 \mathrm{bar}$ & $2.79 \mathrm{bar}$ \\
\hline $\begin{array}{l}\text { Min 10:00-11:00 a.m } \\
\text { Average }\end{array}$ & $1.42 \mathrm{bar}$ & $1.40 \mathrm{bar}$ & $0.85 \mathrm{bar}$ \\
\hline
\end{tabular}

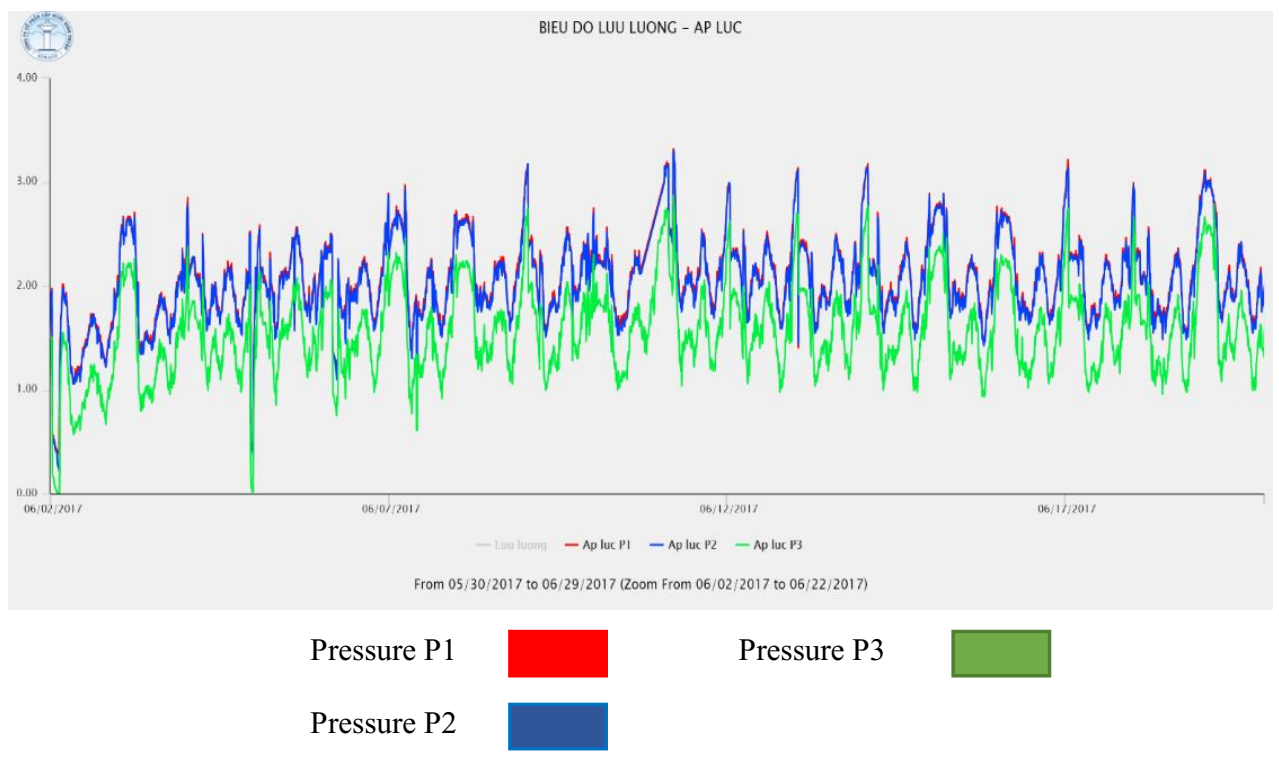

Fig. 6. Curve of Pressure - Flowrate before pressure regulating.

The results of input pressure monitoring and pressure points P1, P2, P3 showed that at low demand hours, pressure P3 was up to 2.79 bar, 1.94 bar higher than the minimum pressure, this was Excessive unnecessary pressure can be cut to reduce the rate of mechanical water loss during night time due to leakage. According to Vietnam standards, pressure requirements at each point of the water supply network must be at least 0.1 bar. The research conducted pilot setting pressure reducing valve in two stages. Pressure control schedule.

Stage 01: (21-06 to 30-06-2017): Maintain downstream pressure at setpoint, Pressure P2 $=1.7$ bar.

Table 3. Report of Flow - Pressure (From 23-06-2017 to 30-06-2017).

\begin{tabular}{|l|c|r|r|r|}
\hline & Flow & P1 Presure & P2 Pressure & P3 Pressure \\
\hline Max & $38.04 \mathrm{~m} 3 / \mathrm{h}$ & $3.34 \mathrm{bar}$ & $1.93 \mathrm{bar}$ & $1.51 \mathrm{bar}$ \\
\hline Min & $10.92 \mathrm{~m} 3 / \mathrm{h}$ & $0.96 \mathrm{bar}$ & $0.96 \mathrm{bar}$ & $0.53 \mathrm{bar}$ \\
\hline Average & $24.63 \mathrm{~m} 3 / \mathrm{h}$ & $2.15 \mathrm{bar}$ & $1.66 \mathrm{bar}$ & $1.19 \mathrm{bar}$ \\
\hline Average per day & $591 \mathrm{~m} 3 /$ day & & & \\
\hline
\end{tabular}

Stage 02: (01-07 to 29-07-2017): Maintain downstream pressure at dual-setpoint

- High demand 05:00 - 22:00: High pressure ( $\mathrm{P} 2=1.7$ bar)

- Low demand 22:00 - 05:00: Low pressure (P2 = 0.9 bar) 
Table 4. Report of Flow - Pressure (From 15-07-2017 to 22-07-2017).

\begin{tabular}{|l|r|r|r|r|}
\hline & \multicolumn{1}{|c|}{ Flow } & P1 Presure & P2 Pressure & P3 Pressure \\
\hline Max & $36.48 \mathrm{~m} 3 / \mathrm{h}$ & $3.07 \mathrm{bar}$ & $1.93 \mathrm{bar}$ & $1.47 \mathrm{bar}$ \\
\hline Min & $6.48 \mathrm{~m} 3 / \mathrm{h}$ & $1.38 \mathrm{bar}$ & $0.55 \mathrm{bar}$ & $0.16 \mathrm{bar}$ \\
\hline Average & $23.04 \mathrm{~m} 3 / \mathrm{h}$ & $2.08 \mathrm{bar}$ & $1.48 \mathrm{bar}$ & $1.02 \mathrm{bar}$ \\
\hline Average per day & $553 \mathrm{~m} 3 /$ day & & & \\
\hline
\end{tabular}

The LS-V Datalogger controls the 3-way solenoid valve on the pressure reducing valve to switch between high pressure and low pressure mode. The chart below shows the pressure correlation before and after two modes of pressure regulation.

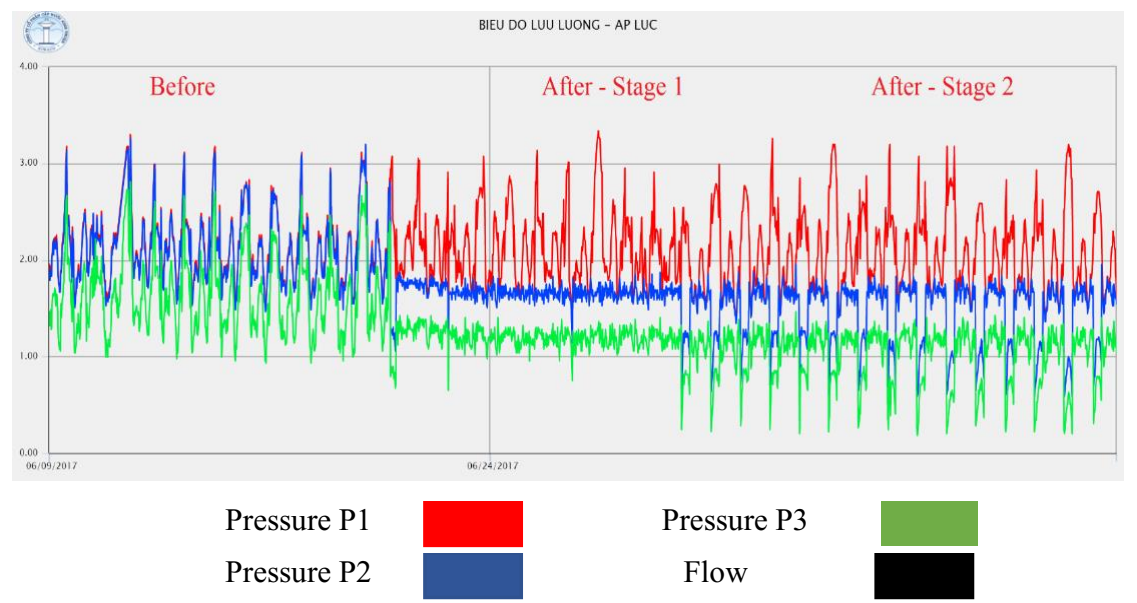

Fig. 7. Curve of pressure before and after pressure regulating.

\section{Results}

Hydraulic generator renewable energy. Based on the average daily flow, monitoring Hydroturbine parameters from $29 / 05 / 2017$ to $06 / 06 / 2017$, the electricity generated by the flow as follows:

Table 5. Power generated and consumed of Hydroturbine.

\begin{tabular}{|c|c|c|}
\hline Date & $\begin{array}{c}\text { Gernerator Power } \\
(\mathrm{W})\end{array}$ & $\begin{array}{c}\text { Power consumption } \\
(\mathrm{W})\end{array}$ \\
\hline $29 / 05 / 2017$ & 0.807 & 0.017 \\
\hline $30 / 05 / 2017$ & 0.773 & 0.016 \\
\hline $31 / 05 / 2017$ & 0.898 & 0.016 \\
\hline $01 / 06 / 2017$ & 0.699 & 0.016 \\
\hline $02 / 06 / 2017$ & 0.728 & 0.016 \\
\hline $03 / 06 / 2017$ & 0.831 & 0.017 \\
\hline $04 / 06 / 2017$ & 0.737 & 0.017 \\
\hline $05 / 06 / 2017$ & 0.733 & 0.017 \\
\hline $06 / 06 / 2017$ & 0.748 & 0.059 \\
\hline
\end{tabular}


Calculated results show that the Hydroturbine Device generates enough power to supply the LS-V Datalogger with continuous and stable operation.

Regulate pressure in DMA

Comparing the average daily flow after 02 stages of pressure regulating

- Stage 1: Average daily flow reducing from $644 \mathrm{~m} 3 /$ day -> $591 \mathrm{~m} 3 /$ day: Save 53.0 $\mathrm{m} 3 /$ day $(8.2 \%)$

- $\quad$ Stage 2: Average daily flow reducing from $644 \mathrm{m3} /$ day -> $553 \mathrm{~m} 3 /$ day: Save91.0 $\mathrm{m} 3 /$ day $(14.1 \%)$

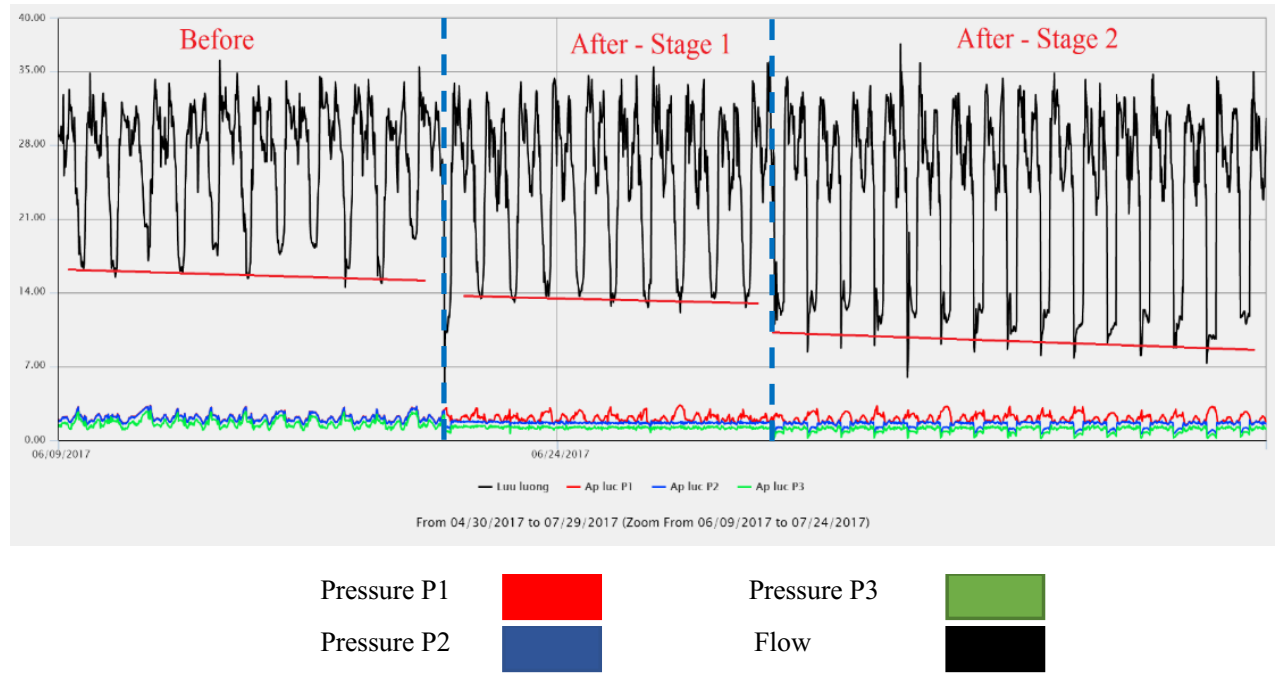

Fig. 8. Curve of Pressure - Flowrate before and after pressure regulating.

The curve above shows that the minimum night flow has decreased after pressure regulation

Comparing the minimum flow during off-peak periods before and during the pressure regulating, it was found that reducing the off-peak pressure from 2.11 bar (before pressure control) to 1.7 bar and 0.9 bar (during automatic pressure regulating) would reduce flow through bulk meter $8.2 \%$ and $14.1 \%$ of DMA total flow. This reduced flow is the loss of water that is reduced by regulating the pressure in the DMA.

\section{Conclusions}

Hydraulic generator renewable energy.

The Ngo Quyen DMA has a small scale, with a small supply of water so that the generated electricity is just enough to operate the LS-V datalogger. But when installed in the pipe with enough flowrate or large pipelines, installed on by-pass to limit the pressure loss on the main tube, at 6 "diameter, the generated power can be up to $20 \mathrm{~W}$ for the flow rate of $150 \mathrm{~m} 3 / \mathrm{h}$. Electricity can be used for serveral devices at the same time with fully calculated power. 


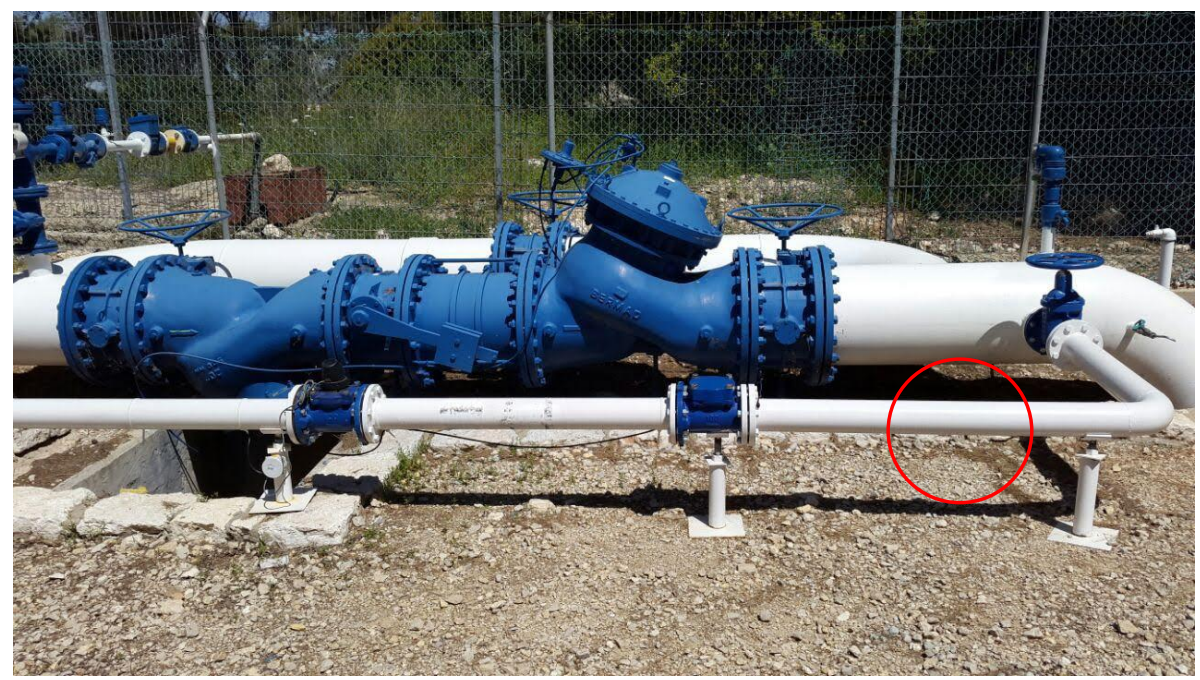

Fig. 9. Hydroturbine provided power with a 4" Swing unit for 20"-diameter pipes right near the reservoir.

In above picture, the unit was installed using a 4" bypass and the partial closing of a valve so that a minimum of 20-30 m3per hour flow through the bypass and spin the turbine. The power is produced to operate a MOSCAD $\AA$ controller.

Therefore, the hydraulic power generation is renewable energy solutions that can be applied on wide variety of water supply network, in many installation conditions and different size pipe. When installing it should be noted that the pressure loss when passing through the mini generator, this pressure loss can be very high with low pressure places, affecting the pressure of water users.

Regulate pressure in DMA

Active pressure regulation at input according tocritical points needs to be rapidly deployed on a large scale. However, when implementing pressure regulation to critical point, it is necessary to consider the most appropriate thresholds for each District Metering Area (DMA), based on the characteristics of consumption and timepattern of main water user in water supply area. Qualitative and quantitative determination of losses in each water supply area should be carried out before implementation the solutions to reduce water loss [28, 29].

This is necessary, because in a situation where the water supply network is severely degraded, leakage prevention by leak detection does not solve the problem of new leakage points after repairing. When regulating low pressure, the flow through the customer meter is also reduced. Therefore, it is necessary to study the correlation between water pressure and demand of customers when implementing regulation. If calculated, maintaining a sufficient pressure for living needs will help to save the water used in the tap. This will reduce the burden of water supply to water treatment plants.

The Ninh Thuan Water Supply Company also noted previously in the DMAs behind DMA Ngo Quyen (after crossing the Thong Nhat Bridge) the pressure was usually very low, but after the installation of the pressure regulator, pressure increased. This shows that pressure regulation not only reduces water loss, but also transfers excess pressure at DMA Ngo Quyen to lower pressure areas, which increases the quality of water supply services. 


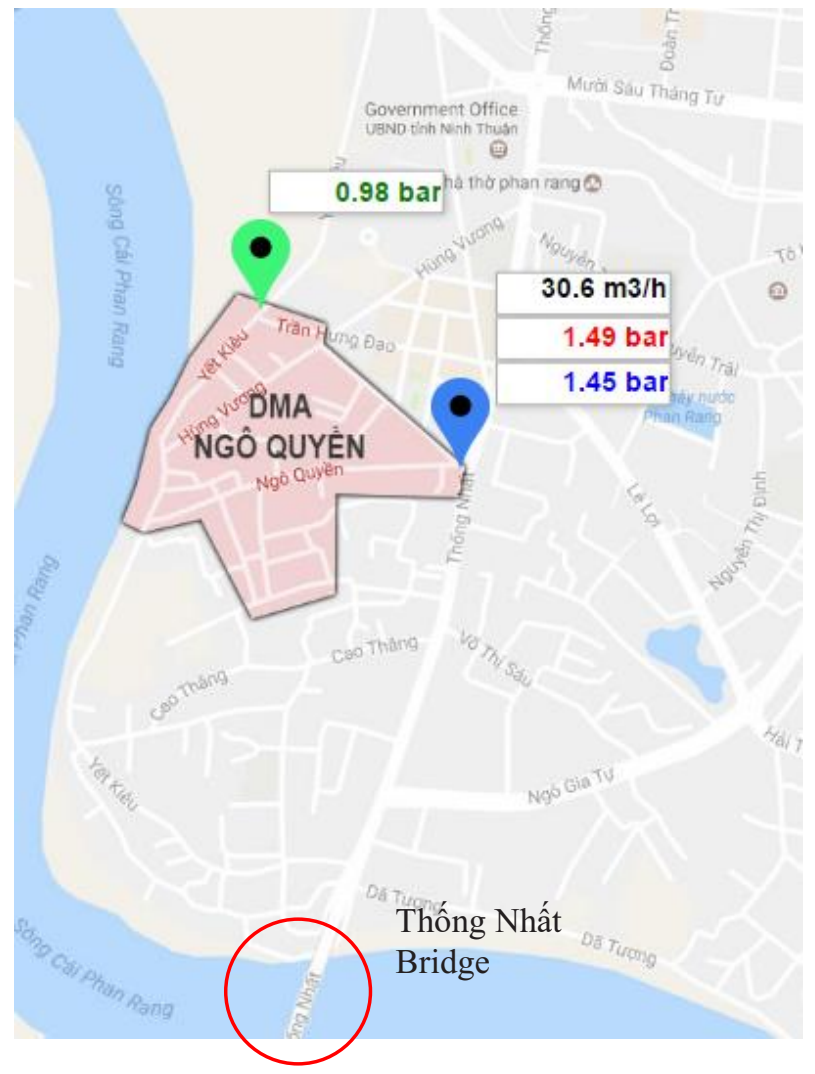

Fig. 10. DMA Ngo Quyen and around area.

Next research direction

In the next research, the author will study the correlation in terms of pressure between DMAs in a water supply area after pressure reducing valve installation.

\section{References}

1. Ministry of Construction, TCXDVN 33-2006, Water Supply - Pipeline and Works Design Standards (Hanoi, 2006)

2. Do Minh Tuan, Water Supply and Sewerage 6(98), $42-44$ (2014)

3. Lam Vu, Water Supply and Sewerage 6(81), 26-27 (2011)

4. Le Trinh, Environmental Impact Assessment, Methods and Applications (Science and Technology Publishing House, Hanoi, 2000)

5. Que Chi Que, Water supply and drainage 86, 35 (2012)

6. Le Phuoc Thanh, Water Supply and Sewerage 3(90)T4, 30-31 (2013)

7. Sai Gon, Water Loss Rate Report (Water Supply Corporation, Ho Chi Minh, 2013)

8. Vo Anh Tuan, Reducing water loss for the city water supply network, International Conference on IENR (IER-VNU), 350-360 (2010)

9. Vo Anh Tuan, Journal of Natural Resources and Environment 22, 156 (2012)

10. Vo Anh Tuan, Journal of Science and Technology - Vietnam Academy of Science and Technology, 53, 228-235 (2015) 
11. L. S. Araujo, H. Ramos, S. T. Coelho, Water Resources Management 20.1,133-149 (2006)

12. L. Berardi, Procedia Engineering 70, 152-161 (2014)

13. B. Kingdom, R. Liemberger, Ph. Marin, The challenge of reducing non-revenue water $(N R W)$ in developing countries. How the private sector can help: A look at performancebased service contracting, World Bank Group (Water Supply \& Sanitation Sector Board, PPIAF, 2006)

14. Dorot Control Valve, Technical Document, Affect of hight and low pressure to flow through leak

15. M. Farley, S. Trow, Losses in Water Distribution Networks (IWA Publishing, London, 2003)

16. M. Farley, A. Malcolm, Leakage management and control: a best practice training manual (2001)

17. R. Frauendorfer, R. Liemberger, The issues and challenges of reducing non-revenue water (Asian Development Bank, 2010)

18. B. Greyvenstein, J. E. Van Zyl, Journal of Water Supply: Research and TechnologyAQUA 56.2, 117-124 (2007)

19. S. Hamilton, When is a DMA not a DMA? Proceedings of IWA Special Conference Water Loss (2007)

20. L. Berardi, S. Liu, D. Laucelli, S. Xu, P. Xu, W. Zeng, O. Giustolisi, Procedia Engineering 70, $152-161$ (2014)

21. A. Lambert, W. Hirner, Losses from water supply systems: standard terminology and recommended performance measures. IWA website (2000)

22. A. Mamade, Procedia Engineering 70, 1063-1073 (2014)

23. M. Tabesh, A.H. Asadiyani Yekta, R. Burrows, Water Resour Manage 23, 77-492 (2008)

24. M. Tabesh, A.H. Asadiyani Yekta, R. Burrows, Water Resources Management 23.3, 477-492 (2009)

25. Xu Qiang, Journal of Environmental Sciences 26.5, 955-961 (2014)

26. J. Sempewo, A. Pathirana, K. Vairavamoorthy, Water Distribution Systems Analysis 2008, 1-15 (2008) 